\title{
World Journal of Predictive factors for time to full enteral Pediatric Surgery feeding after pyloromyotomy for infantile hypertrophic pyloric stenosis
}

\author{
David Eriksson, ${ }^{1}$ Martin Salö ${ }^{1,2}$
}

To cite: Eriksson D, Salö M. Predictive factors for time to full enteral feeding after pyloromyotomy for infantile hypertrophic pyloric stenosis. World Jnl Ped Surgery 2020;3:e000081. doi:10.1136/ wjps-2019-000081

- Additional material is publishe
online only. To view please visit the journal online (http://dx.doi. org/10.1136/wjps-2019-000081)

Received 21 August 2019 Revised 11 February 2020 Accepted 12 February 2020

\section{Check for updates}

C Author(s) (or their employer(s)) 2020. Re-use permitted under CC BY-NC. No commercial re-use. See rights and permissions. Published by BMJ.

${ }^{1}$ Department of Clinical Sciences, Pediatrics, Lund University, Lund, Sweden 2Department of Pediatric Surgery, Skåne University Hospital, Lund, Sweden

Correspondence to Dr Martin Salö; martin.salo@ med.lu.se

\section{ABSTRACT}

Background The aim of the study was to evaluate how different parameters in the preoperative, perioperative, and postoperative period affect time to full enteral feeding (TFEF) in children undergoing pyloromyotomy.

Methods A retrospective study of all children operated for infantile hypertrophic pyloric stenosis between 2001 and 2017 was conducted. Parameters in demographics and in the preoperative and postoperative period were evaluated against TFEF (hours) using linear regression models.

Results In the whole cohort of 175 children, mean TFEF was 47 hours with Standard Deviation (SD) of \pm 35 . In the multivariate model, TFEF decreased with age [beta (B): $-0.62 ; 95 \%$ confidence interval $(95 \% \mathrm{Cl})-1.05$ to -0.19 ; $\mathrm{p}=0.005$ ) and increased with the presence of severe underlying disease (congenital heart defect or syndrome) (B: 26.5; 95\% Cl 3.3 to $49.7 ; p=0.026$ ). Hence, for every day of age, the time to fully fed decreased by 0.6 hour, and the presence of an underlying disease increased the time to fully fed with over one day. TFEF did not seem to be affected by prematurity, weight loss, symptom duration, preoperative acid/base balance or electrolyte values, surgical method, or method of postoperative feeding. Conclusions TFEF decreased with higher age and increased in children with a severe underlying disease. These results may be useful in providing adequate parental information regarding what affects TFEF and the length of hospital stay.

\section{INTRODUCTION}

Infantile hypertrophic pyloric stenosis (IHPS) is a relatively common disease with an incidence of 2-4 per 1000 live births in Western populations. ${ }^{1}$ Most studies regarding outcome after surgery for IHPS, in terms of time to full enteral feeding (TFEF) or length of hospital stay, focus on surgical method ${ }^{23}$ or method of postoperative feeding. ${ }^{45}$ Less is known whether patient characteristics, symptoms and signs of dehydration, or other variables in the preoperative phase can affect the outcome, and especially TFEF after pyloromyotomy. Therefore, the aim of this study was to examine which parameters could affect the TFEF in children operated on with pyloromyotomy for IHPS, with focus on patient's characteristics, preoperative symptoms and signs

\section{Summary box}

What is already known about this subject?

- Infantile hypertrophic pyloric stenosis is a common disease.

- Time to full goals after surgery seem to be affected by the degree of preoperative electrolyte disturbances.

> There is no study adjusting for confounding factors that has evaluated other parameters that may affect TFEF after surgery.

What are the new findings?

- TFEF decreased with higher age and increased in children with a severe underlying disease.

- No evidence was found for parameters reflecting preoperative emesis (symptom duration, weight change, electrolyte abnormalities) affecting TFEF.

How might it impact on clinical practice in the foreseeable future?

- This study can be used to improve parental information. It also suggests that trials comparing different operation techniques or postoperative feeding regimens adjust their results for age at surgery and underlying diseases.

of dehydration including laboratory values. Our hypothesis was that metabolic alkalosis and/or hypochloremia at admission, even if corrected before surgery, and symptom duration, increased the risk of longer duration to full enteral feeds. If influenceable parameters were proved to increase the risk of longer duration to full enteral feeds, a modified

preoperative treatment could possibly reduce the time to full feeds, and in the long run shorten length of postoperative hospital stay. Also, being able to better estimate time to full enteral feeds and duration of postoperative hospital stay is valuable when giving information to caregivers.

\section{METHODS}

Settings and children

All children were treated at a tertiary center for pediatric surgery with a catchment area 


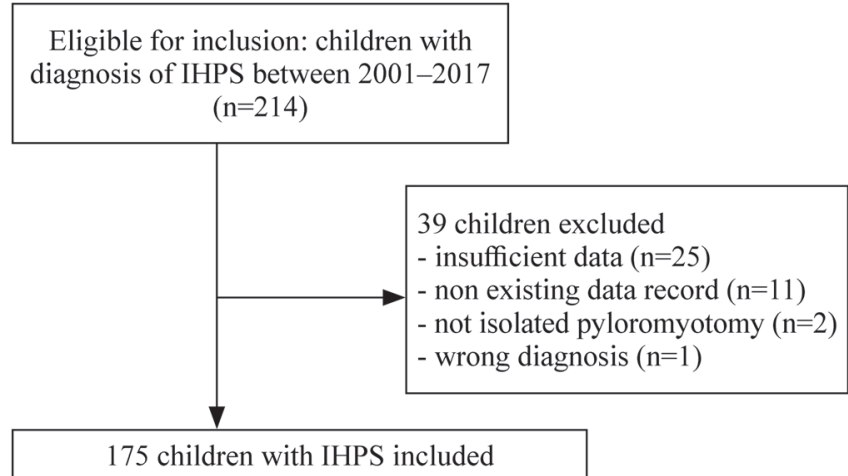

Figure 1 Flow chart of inclusion and exclusion of children operated for infantile hypertrophic pyloric stenosis (IHPS) 2001-2017.

of around 1.8 million inhabitants for specialized pediatric surgery in children up to 15 years. All patients with an International Classification of Diseases 10th Revision diagnosis code of Q.40.0 who underwent pyloromyotomy from 2001 to 2017 were eligible for inclusion. Inclusion criteria were diagnosis of isolated IHPS and isolated pyloromyotomy operation. Children with insufficient data for retrieving TFEF were excluded. Laparoscopic pyloromyotomy was not used at our department during the study period. The diagnosis of IHPS was based on clinical symptoms and ultrasound findings. The postoperative feeding was initiated by the operating surgeon and started 3-4hours after surgery with either free feeding or according to a schedule. The specific feeding schedule started with $20 \%$ of the full amount $(150 \mathrm{~mL} / \mathrm{kg})$, and increases with $20 \%$ for every meal; if significant vomiting occured, the same amount would be given again at the next meal.

\section{Study design}

This study is an institution-based retrospective study. Primary outcome was duration (hours) to full enteral feeding. This was defined by the time from operation to journal notes either stated 'fully fed' or describing correct amount of food intake without emesis. Independent variables were preoperative parameters such as demographical data, type of feeding (breastmilk/ formula), symptoms and blood tests; surgical data such as method of operation; and postoperative parameters including method of feeding and complications. Prematurity was defined as a gestational age shorter than 37 weeks. Age at operation was corrected for prematurity. Small for gestational age was defined as a weight below the 10th percentile for the gestational age. Children with congenital heart disease (CHD) requiring surgery, and syndromes were included in the 'severe underlying disease' group. The cut-offs used for ultrasound were pyloric muscle thickness of $4 \mathrm{~mm}$ or more, and pyloric channel length of $16 \mathrm{~mm}$ or more. ${ }^{6}$ In infants small than 3 weeks the cut-off for thickness was $3.5 \mathrm{~mm} .{ }^{7}$ Blood samples were taken from venous blood to perform analysis of sodium, potassium, chloride, base excess,
Table 1 Demographics, preoperative data and surgical method in 175 children with infantile hypertrophic pyloric stenosis

\begin{tabular}{|c|c|c|}
\hline Gender (male) & \multicolumn{2}{|l|}{$148(85 \%)$} \\
\hline Age (days) & \multicolumn{2}{|l|}{$40 \pm 17$} \\
\hline Breast feeding & \multicolumn{2}{|l|}{$127(73 \%)$} \\
\hline Gestational age & \multicolumn{2}{|c|}{$39+4(27+4$ to $42+1)$} \\
\hline Premature & \multicolumn{2}{|c|}{$24(14 \%)$} \\
\hline Corrected age (days) & \multicolumn{2}{|l|}{$37 \pm 17$} \\
\hline SGA & \multicolumn{2}{|l|}{$13(7 \%)$} \\
\hline Weight (g) & \multicolumn{2}{|l|}{$3925 \pm 873^{*}$} \\
\hline Weight loss & \multicolumn{2}{|l|}{$128(74 \%) \dagger$} \\
\hline Severe underlying disease & \multicolumn{2}{|l|}{$12(7 \%)$} \\
\hline Increased bilirubin & \multicolumn{2}{|l|}{$25(14 \%)$} \\
\hline Bilirubin ( $\mu \mathrm{mol} / \mathrm{L})$ & \multicolumn{2}{|l|}{$45(173)$} \\
\hline Duration of symptoms (d) & \multicolumn{2}{|l|}{$4(7)$} \\
\hline Acid base balance & First & Last \\
\hline Metabolic acidosis & $2(1 \%) \ddagger$ & $2(1 \%) \S$ \\
\hline Metabolic alkalosis & 49 (29\%)‡ & $0(0 \%) \S$ \\
\hline Base excess & $\begin{array}{l}4.6(-8.0 \text { to } \\
22.7) \emptyset\end{array}$ & $\begin{array}{l}0.6(-7.4 \text { to } \\
9.0)^{\star \star}\end{array}$ \\
\hline $\mathrm{CO}_{2}$ & $5.8(1.3) \dagger \dagger$ & $5.4(1) \ddagger \ddagger$ \\
\hline Electrolyte balance & First & Last \\
\hline Hyponatremia & 17 (10\%)§§ & 9 (5\%)ๆๆ \\
\hline Chloride & $101(8)^{\star \star \star}$ & 108 (4)††† \\
\hline Lactate & 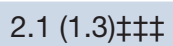 & $1.9(1) \S \S \S$ \\
\hline Preoperative LOH (days) & $2(1)$ & \\
\hline \multicolumn{3}{|l|}{ Operation } \\
\hline Umbilical incision & \multicolumn{2}{|l|}{$98(57 \%)$} \\
\hline $\begin{array}{l}\text { Right upper quadrant } \\
\text { incision }\end{array}$ & \multicolumn{2}{|l|}{$75(43 \%)$} \\
\hline
\end{tabular}

Values presented as absolute numbers and percentage of patients; $\mathrm{n}(\%)$, mean \pm SD, median (min to max) or as median (IQR).

*Lacking data for 7 patients. †Lacking data for 1 patient.

łLacking data for 6 patients.

§Lacking data for 8 patients.

ףLacking data for 6 patients.

**Lacking data for 9 patients.

††Lacking data for 6 patients.

¥¥Lacking data for 8 patients.

$\S \S$ Lacking data for 7 patients.

१ๆlacking data for 7 patients.

*** Lacking data for 52 patients.

†††Lacking data for 31 patients.

$\ddagger \ddagger$ Lacking data for 40 patients.

$\S \S \S$ Lacking data for 5 patients.

$\mathrm{LOH}$, length of hospital stay; SGA, small for gestational age.

$\mathrm{pH}, \mathrm{pCO}_{2}, \mathrm{pO}_{2}$, hemoglobin, and liver function tests including alanine transaminase, aspartate transaminase, alkaline phosphatase, gamma-glutamyl transpeptidase, and bilirubin (total). Reference intervals for all analyses were age specific and followed international standards. ${ }^{8}$ 
Table 2 Postoperative data and outcome in 175 children operated for infantile hypertrophic pyloric stenosis

\begin{tabular}{ll}
\hline Method of feeding* & \\
\multicolumn{1}{c}{ Ad libitum } & $20(12 \%)$ \\
\hline \multicolumn{1}{c}{ Scheduled } & $154(88 \%)$ \\
\hline Time fully fed (hours) & $47 \pm 35$ \\
Complications & $7(4 \%)$ \\
\hline Reoperation & $4(2 \%)$ \\
Postoperative LOH (hours) & $66 \pm 44$ \\
Readmission (<30 days) & $6(3 \%) \dagger$ \\
\hline
\end{tabular}

Values presented as absolute numbers and percentage of patients; $n(\%)$ and mean \pm SD.

*Only 174 patients with data.

†Readmission due to surgical site infection $(n=4)$, incomplete myotomy $(n=1)$ and incisional hernia $(n=1)$.

$\mathrm{LOH}$, length of hospital stay.

Table 3 Univariate regression of demographics, preoperative and postoperative data and the effect on time in hours to full enteral feeding

\begin{tabular}{|c|c|c|}
\hline Variable & B $(95 \% \mathrm{Cl})$ & P value \\
\hline Gender (male) & $-12.5(-26.37$ to 1.36$)$ & 0.077 \\
\hline Corrected age (days) & $-0.64(-0.91$ to -0.36$)$ & $<0.001$ \\
\hline Breast feeding (yes) & $-2.8(-14.1$ to 8.54$)$ & 0.629 \\
\hline Premature (yes) & $7.3(-7.35$ to 21.95$)$ & 0.327 \\
\hline SGA (yes) & $15.3(-4.5$ to 35.15$)$ & 0.131 \\
\hline Weight (kg) & $-4.9(-9.47$ to -0.53$)$ & 0.004 \\
\hline Weight loss (yes) & $-1.7(-13.16$ to 9.77$)$ & 0.771 \\
\hline $\begin{array}{l}\text { Severe underlying disease } \\
\text { (yes) }\end{array}$ & 34.2 (14.88 to 53.5$)$ & 0.001 \\
\hline Increased bilirubin (yes) & 20.9 (7.28 to 35.54$)$ & 0.003 \\
\hline Bilirubin ( $\mu \mathrm{mol} / \mathrm{L})$ & $-0.03(-0.172$ to 0.121$)$ & 0.731 \\
\hline Duration of symptoms & $-0.79(-1.53$ to -0.042$)$ & 0.038 \\
\hline \multicolumn{3}{|l|}{ First acid base balance } \\
\hline $\mathrm{pH}$ & $-5.6(-79.9$ to 68.69$)$ & 0.881 \\
\hline Base excess & $0.59(-0.66$ to 1.83$)$ & 0.352 \\
\hline $\mathrm{pCO}_{2}$ & $4.4(-0.43$ to 9.27$)$ & 0.074 \\
\hline \multicolumn{3}{|l|}{ First electrolyte balance } \\
\hline Sodium (mmol/L) & $0.93(-1.05$ to 2.91$)$ & 0.354 \\
\hline Chloride (mmol/L) & $0.35(-0.55$ to 1.25$)$ & 0.442 \\
\hline Lactate (mmol/L) & $-1.7(-6.48$ to 3.04$)$ & 0.475 \\
\hline Operation (umbilical) & $-1.4(-11.70$ to 8.85$)$ & 0.785 \\
\hline Method of feeding & $14.5(-1.28$ to 30.28$)$ & 0.071 \\
\hline Reoperation (yes) & $0.12(-33.1$ to 33.15$)$ & 0.996 \\
\hline Complication (yes) & $2.15(-22.1$ to 26.3$)$ & 0.861 \\
\hline
\end{tabular}

Linear regression presented as beta $(\mathrm{B})$ with $95 \% \mathrm{Cls}$.

Signifcant $p$-values $(<0.05)$ in bold.

SGA, small for gestational age.
The reference intervals for (total) bilirubin were: $<2$ days of age: $<100 \mu \mathrm{mol} / \mathrm{L} ; 2-6$ days of age: $<200 \mu \mathrm{mol} / \mathrm{L} ; 7-20$ days of age: $<100 \mu \mathrm{mol} / \mathrm{L} ; 21-29$ days: $<50 \mu \mathrm{mol} / \mathrm{L}$; and $>1$ month of age: $<22 \mu \mathrm{mol} / \mathrm{L}$. Complications included were postoperative infection and reoperation. Length of postoperative hospital stay (hours) was counted from operation until discharge.

\section{Statistical analyses}

Statistical analyses were performed using IBM SPSS Statistics for Mac, V.24 (IBM). Continuous variables were presented as median or interquartile range (IQR) (no normal distribution) or mean \pm SD (normal distribution). Normal distribution was tested by evaluation of skewness and kurtosis. Dichotomous variables were presented as the absolute number and percentage of patients. The primary outcome of full enteral feeding was treated as a continuous parameter and different parameters were tested as independent variables, first in a univariate and then in a multivariate linear regression model. The results were presented as beta (B) with $95 \%$ confidence interval (CI). Reoperations and complications were also added to the regression analyses since they might have an impact on feeding.

Collinearity between the continuous parameters was evaluated. If moderate to strong correlation existed, the final regression model would be tested with and without the different variable(s). Further, we checked for heteroscedasticity by plotting the residuals of the final regression model against patients' age. A $p$ value $<0.05$ was considered to be statistically significant.

\section{RESULTS}

From 2001 to 2017, a total of 214 children were diagnosed and operated on for IHPS. A total of $39(18 \%)$ patients were excluded; 25 for missing data, 11 for nonexisting data record, 2 for non-isolated pyloromyotomy, and 1 for wrong diagnosis; leaving a total of 175 children included in the study (figure 1).

The included cohort consisted of 148 (85\%) boys, with a mean corrected age of 37 days, a mean weight of 3925 g, $24(14 \%)$ of which were premature, and $12(7 \%)$ of which had a severe underlying disease (online supplementary table 1). Median duration of symptoms was 4 days (IQR: 7); 128 patients (74\%) experienced weight loss; and increased bilirubin was seen in 25 patients (14\%) (table 1).

Mean TFEF for the whole cohort was $47 \pm 35$ hours and mean length of postoperative hospital stay was $66 \pm 44$ hours. The majority of children $(88 \%)$ were fed according to a feeding schedule. No child required intravenous nutrition. There were seven children (4\%) presented with postoperative complications, of which four required reoperation (table 2).

In the univariate analysis, age, weight, severe underlying disease increased bilirubin level, and duration of symptoms were found to affect TFEF (table 3). In the 


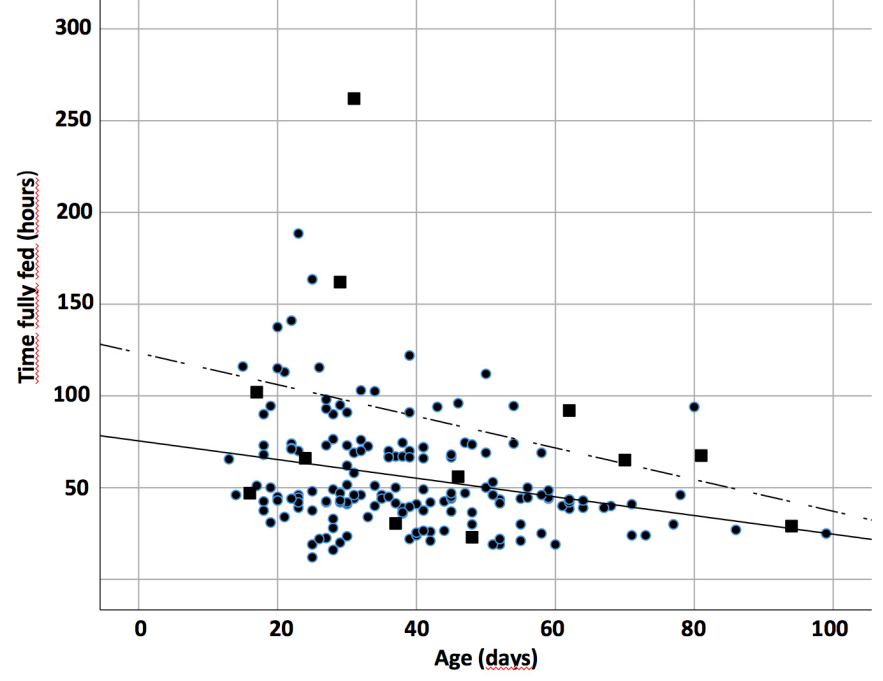

Figure 2 Scatterplot over the correlation between age in days and hours to fully fed in 175 children operated for infantile hypertrophic pyloric stenosis. $\square$ Patients with underlying disease; - denotes age; --- denotes underlying diseases.

multivariate analysis, only age (B: $-0.62(95 \%$ CI -1.05 to -0.19$), \mathrm{p}=0.005$ ) (figure 2) and severe underlying disease (B: 26.5 (95\% CI 3.3 to 49.7), $\mathrm{p}=0.026$ ) remained as variables significantly affecting TFEF (table 4 ). Hence, for every day of age, the time to fully fed decreased with 0.6 hour, and the presence of an underlying disease increased the time to fully fed with over 1 day. TFEF did not seem to be affected by prematurity, preoperative weight loss, symptom duration, preoperative acid/base balance or electrolyte values, surgical method, or method of postoperative feeding (tables 3 and 4).

The correlation between the different continuous parameters was overall weak (Spearman's correlation coefficient $\left(\mathrm{r}_{\mathrm{s}}\right)$ between -0.1 and 0.1$)$, except the correlation between age and weight $\left(\mathrm{r}_{\mathrm{s}}: 0.41\right)$. The final regression model was tested with and without the weight included and there was little difference in the beta for age $(-0.62,95 \%$ CI -1.05 to -0.19 and $-0.61,95 \%$ CI -0.98 to -0.25 , respectively). When checking for heteroscedasticity, the residuals of the final regression model seemed to have constant variance (data not shown).

\section{DISCUSSION}

In children who underwent pyloromyotomy for IHPS, a higher age decreased TFEF, while presence of underlying disease was associated with increased duration.

There is a significant value in evaluating preoperative factors as predictors for worse postoperative outcome. Such evaluations improve preoperative and postoperative information to caregivers; they also provide a way to improve preoperative and postoperative care. Further, being able to stratify patients in different risk groups would be of great importance in future studies evaluating different surgical methods or different postoperative feeding regimens, as described earlier. ${ }^{4}$ We evaluated
Table 4 Multivariate linear regression of variables predicting longer time in hours to full enteral feeding in 175 children operated for infantile hypertrophic pyloric stenosis

\begin{tabular}{lcl}
\hline Variable & B (95\% Cl) & P value \\
\hline Gender (male) & $-9.84(-26.12$ to 6.44$)$ & 0.234 \\
\hline Corrected age (days) & $-0.62(-1.05$ to -0.19$)$ & $\mathbf{0 . 0 0 5}$ \\
\hline Breast feeding (yes) & $-2.29(-15.06$ to 10.46$)$ & 0.723 \\
\hline Premature (yes) & $12.08(-10.08$ to 34.24$)$ & 0.283 \\
\hline SGA (yes) & $4.26(-23.53$ to 32.05$)$ & 0.762 \\
Weight (kg) & $-2.1(-3.4$ to 0.56$)$ & 0.832 \\
Weight loss (yes) & $-1.12(-14.35$ to 12.12$)$ & 0.867 \\
$\begin{array}{l}\text { Severe underlying } \\
\text { disease (yes) }\end{array}$ & $26.49(3.29$ to 49.71$)$ & $\mathbf{0 . 0 2 6}$ \\
$\begin{array}{l}\text { Increased bilirubin } \\
\text { (yes) }\end{array}$ & $4.31(-11.71$ to 20.32$)$ & 0.596 \\
$\begin{array}{l}\text { Duration of } \\
\text { symptoms (hours) }\end{array}$ & $-0.10(-1.07$ to 0.87$)$ & 0.841 \\
\hline
\end{tabular}

First acid base balance

$\begin{array}{lcc}\mathrm{pH} & 36.48(-151.39 \text { to } 224.35) & 0.702 \\ \text { Base excess } & 0.43(-2.17 \text { to } 3.04) & 0.743 \\ \mathrm{pCO}_{2} & 2.78(-6.85 \text { to } 12.41) & 0.569\end{array}$

First electrolyte balance

\begin{tabular}{|c|c|c|}
\hline Sodium (mmol/L) & $1.14(-1.22$ to 3.51$)$ & 0.340 \\
\hline Chloride (mmol/L) & $-0.58(-5.99$ to 4.83$)$ & 0.833 \\
\hline Lactate (mmol/L) & $-1.02(-5.73$ to 2.51$)$ & 0.652 \\
\hline $\begin{array}{l}\text { Operation (umbilical } \\
\text { incision) }\end{array}$ & $-2.39(-13.51$ to 8.72$)$ & 0.671 \\
\hline $\begin{array}{l}\text { Method of feeding } \\
\text { (schedule) }\end{array}$ & 7.41 (-9.66 to 24.47$)$ & 0.392 \\
\hline Reoperation (yes) & $-15.15(-39.16$ to 40.2$)$ & 0.589 \\
\hline Complication (yes) & 0.835 (-39.1 to 40.8$)$ & 0.967 \\
\hline
\end{tabular}

Linear regression presented as beta $(\mathrm{B})$ with $95 \% \mathrm{Cls}$. Signifcant $p$-values $(<0.05)$ in bold.

SGA, small for gestational age.

several parameters of patient characteristics, preoperative symptoms and signs of dehydration, including laboratory values, feeding method and operation method, but only two of these parameters appeared to affect TFEF. Our hypothesis that metabolic alkalosis and/or hypochloremia at admission, and symptom duration, would increase the duration of reaching goal feeds was not supported. In addition, neither prematurity, preoperative weight loss, other preoperative acid/base balance or electrolyte values, surgical method, nor method of postoperative feeding had an effect on TFEF. The finding of higher age decreasing and severe underlying disease increasing TFEF is not unexpected. Unfortunately, these parameters also cannot be influenced and we therefore cannot modify our preoperative or postoperative management of children with IHPS based on this study. The strength of this study is that all children were treated at the same center and that the management of children 
with IHPS, besides operation technique, did not change during the study period. Another strength is the full evaluation of several parameters and a multivariate analysis which in comparison with the literature is sparsely conducted before.

A few studies before the present one have tried to evaluate how different preoperative parameters affect postoperative outcome, either defined as emesis, time to goal intake, or length of postoperative hospital stay. A prospective study found that the degree of hypokalemic, hypochloremic, and metabolic alkalosis correlated with the number of postoperative emesis episodes and TFEF. ${ }^{9}$ The authors also concluded that the duration of dehydration and failure to thrive was correlated with poor outcome since there were inverse correlations between the number of episodes of postoperative emesis and time to goal intakes with weight at admission. Results from a randomized trial found that low chloride levels increased TFEF. ${ }^{10}$ Our results do not support either of these results despite roughly the same number of included patients; hence the present study was in that sense not underpowered. The parameters found to cause longer time to full goals in previous studies ${ }^{910}$ were mainly laboratory values that should be less affected by our retrospective design. On the other hand, the primary outcome of TFEF was in the present study extracted from charts and could of course be subject to the disadvantages of a retrospective design. Other studies have found a correlation of postoperative emesis or longer hospital stay (not specifically TFEF) with weight ${ }^{11}$ and age at surgery, ${ }^{12}{ }^{13}$ symptom duration ${ }^{1415}$ and pyloric thickness on ultrasound. ${ }^{12}$

None of these results were supported by our study. However, none of these retrospective studies included a multivariate analysis and the results could therefore be questioned.

A severe underlying disease, defined in our study as CHD requiring surgery, or a syndrome, was also associated with increased risk of longer TFEF. A study of IHPS comparing postoperative outcomes between patients with and without CHD showed that a comorbidity lengthened hospital stay. ${ }^{16}$ In isolated cases of IHPS, time until full feed often equals length of hospital stay, but it seems harder to distinguish the two when a comorbidity is the evaluated factor. We believe that this is due to other treatment requirements which may prolong or hinder the advancement of reaching goal feeds. Children with CHD may also need extra calories.

All children did not have the same postoperative feeding regimen which was known to affect times to full enteral feeds. ${ }^{41718}$ Although this was adjusted in the multivariate analysis, it remained a true limitation since this might be slow down feeding. With the present feeding protocol, no infant could reach full feeds in less than 5 feedsthat is, 15 hours. Further, the retrospective study design which may have affected the precision of which time until full enteral feed could be retrieved. A prospective study would of course perform better regarding exact hours. A third weakness is the sample size of study population which compared with other studies is relatively small despite a long study period.

In conclusion, TFEF decreased with higher age and increased in children with a severe underlying disease. No evidence was found for parameters reflecting preoperative emesis (symptom duration, weight change, electrolyte abnormalities) affecting TFEF. Parental information may be improved by increased knowledge about what affect, and what does not affect, time to full feeds and length of postoperative hospital stay. We suggest that future research examining preoperative, perioperative, and postoperative parameters, or trials comparing different operation techniques or postoperative feeding regimens, when adjusted for corrected age at surgery and presence of underlying diseases.

Acknowledgements The authors thank Anna Åkesson (statistician, Clinical Trial Unit of Forum South, Lund, Sweden) for help with the statistical analyses.

Contributors DE collected the data, drafted the initial manuscript and helped revise the final manuscript. MS conceptualized the design, gathered the cohort, performed the statistical analyses and revised the manuscript. Both authors approved the final manuscript.

Funding The authors have not declared a specific grant for this research from any funding agency in the public, commercial or not-for-profit sectors.

Competing interests None declared.

Patient consent for publication Not required.

Ethical approval This study has been approved by the Regional Ethical Review Board (DNR number 2010/49) and by the regional hospital ethics committee and was done in accordance with the principles outlined in the Declaration of Helsinki.

Provenance and peer review Not commissioned; externally peer reviewed.

Data availability statement Data are available upon reasonable request. Data are available upon request to the author (martin.salo@med.lu.se). The data are in form of deidentified participant data.

Open access This is an open access article distributed in accordance with the Creative Commons Attribution Non Commercial (CC BY-NC 4.0) license, which permits others to distribute, remix, adapt, build upon this work non-commercially, and license their derivative works on different terms, provided the original work is properly cited, appropriate credit is given, any changes made indicated, and the use is non-commercial. See: http://creativecommons.org/licenses/by-nc/4.0/.

\section{REFERENCES}

1 To T, Wajja A, Wales PW, et al. Population demographic indicators associated with incidence of pyloric stenosis. Arch Pediatr Adolesc Med 2005;159:520-5.

2 Sola JE, Neville HL. Laparoscopic vs open pyloromyotomy: a systematic review and meta-analysis. J Pediatr Surg 2009;44:1631-7.

3 Hall NJ, Pacilli M, Eaton S, et al. Recovery after open versus laparoscopic pyloromyotomy for pyloric stenosis: a double-blind multicentre randomised controlled trial. Lancet 2009;373:390-8.

4 Graham KA, Laituri CA, Markel TA, et al. A review of postoperative feeding regimens in infantile hypertrophic pyloric stenosis. $J$ Pediatr Surg 2013;48:2175-9.

5 Carpenter RO, Schaffer RL, Maeso CE, et al. Postoperative ad lib feeding for hypertrophic pyloric stenosis. J Pediatr Surg 1999;34:959-61.

6 Hernanz-Schulman M. Infantile hypertrophic pyloric stenosis. Radiology 2003;227:319-31.

7 Leaphart CL, Borland K, Kane TD, et al. Hypertrophic pyloric stenosis in newborns younger than 21 days: remodeling the path of surgical intervention. J Pediatr Surg 2008;43:998-1001.

8 Colantonio DA, Kyriakopoulou L, Chan MK, et al. Closing the gaps in pediatric laboratory reference intervals: a CALIPER database of 40 biochemical markers in a healthy and multiethnic population of children. Clin Chem 2012;58:854-68.

9 St Peter SD, Tsao K, Sharp SW, et al. Predictors of emesis and time to goal intake after pyloromyotomy: analysis from a prospective trial. J Pediatr Surg 2008;43:2038-41. 
10 Markel TA, Scott MR, Stokes SM, et al. A randomized trial to assess advancement of enteral feedings following surgery for hypertrophic pyloric stenosis. J Pediatr Surg 2017;52:534-9.

11 Tang K-S, Huang I-F, Shih $\mathrm{H}-\mathrm{H}$, et al. Factors contributing to prolonged hospitalization of patients with infantile hypertrophic pyloric stenosis. Pediatr Neonatol 2011;52:203-7.

12 Luciani JL, Allal H, Polliotto S, et al. Prognostic factors of the postoperative vomiting in case of hypertrophic pyloric stenosis. Eur J Pediatr Surg 1997;7:93-6.

13 Huang I-F, Tiao M-M, Chiou CC, et al. Infantile hypertrophic pyloric stenosis before 3 weeks of age in infants and preterm babies. Pediatr Int 2011:53:18-23.

14 Lee SL, Stark R. Can patient factors predict early discharge after pyloromyotomy? Perm J 2011;15:44-6.
15 Al-Jazaeri A, Al-Shehri A, Zamakhshary M, et al. Can the duration of vomiting predict postoperative outcomes in hypertrophic pyloric stenosis? Ann Saudi Med 2011;31:609-12.

16 Miyata S, Cho J, Matsushima K, et al. Operative outcomes of infantile hypertrophic pyloric stenosis in patients with congenital heart disease. J Pediatr Surg 2016;51:1755-8.

17 Leinwand MJ, Shaul DB, Anderson KD. A standardized feeding regimen for hypertrophic pyloric stenosis decreases length of hospitalization and hospital costs. J Pediatr Surg 2000;35:1063-5.

18 Adibe OO, Nichol PF, Lim F-Y, et al. Ad libitum feeds after laparoscopic pyloromyotomy: a retrospective comparison with a standardized feeding regimen in 227 infants. J Laparoendosc Adv Surg Tech A 2007;17:235-7. 